\title{
The view of \#schizophrenia on Twitter (a splitting of the mind in 280 characters)
}

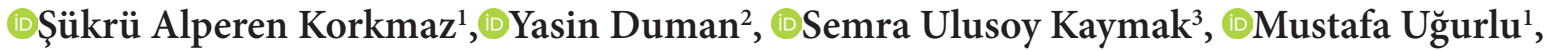

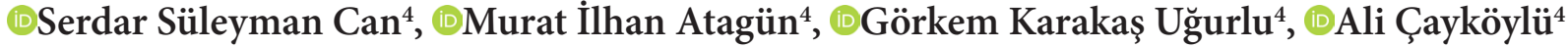 \\ ${ }^{1}$ Ankara City Hospital, Departmen of Psychiatry, Ankara, Turkey \\ ${ }^{2}$ Polatlı State Hospital, Department of Psychiatry, Polatl, Ankara, Turkey \\ ${ }^{3}$ Ministry of Health, Directorate General of Health Services, Ankara, Turkey \\ ${ }^{4}$ Ankara Yıldırım Beyazıt University, Faculty of Medicine, Department of Psychiatry, Ankara, Turkey
}

Cite this article as: Korkmaz ŞA, Duman Y, Ulusoy Kaymak S, et al. The view of \#schizophrenia on Twitter (a splitting of the mind in 280 characters). J Health Sci Med 2021; 4(1): 91-95.

\begin{abstract}
Aim: Posts about an important public health problem, schizophrenia, are increasing on Twitter, whose user number is multiplying every day. This disorder of complex aetiology is often stigmatized with society. In this study, we investigate the perspectives and attitudes of the community surrounding the terms "schizophrenia", "schizophrene", "schizophrenic", and "paranoiac" on Twitter in Turkey.

Material and Method: For approximately one month, a total of 1200 tweets containing the terms "schizophrenia", "schizophrene", "schizophrenic" or "paranoiac" were analysed and compared to their usage in a pilot sample. After establishing inter-rater reliability, the contexts of these terms were sorted into five main categories: a) mocking/humorous b) negative c) inappropriate d) anti-psychiatric e) medically appropriate. When possible, the age and gender of the posters were also recorded.

Results: It was seen that these four words were usually used in "mocking/humorous" (39.2\%) or "negative" (26\%) contexts. The predominant use of the words was in a non-medical manner, with the most medically appropriate usage belonging to "schizophrenia" (26.7\%) and the most "negative" and "mocking/humorous" usage belonging to "schizophrenic" (33.2\% and $45.8 \%$, respectively). In terms of gender, the four words were used mocking/humorous nearly equally by both genders ( $39.5 \%$ and $38.8 \%$, respectively). Medically appropriate use was seen more often in posts by women than in posts by men $\quad(14.8 \%$ vs $7.5 \%$, respectively).

Conclusion: Our findings reveal a great deal of misuse of the term "schizophrenia" and its related words on Twitter. This misuse is quite pronounced in the "schizophrenic", which is adjective forms of the word schizophrenia . At this time, where information is readily available, the stigma, ignorance and attitude problems towards schizophrenia are at an notable level.
\end{abstract}

Keywords: schizophrenia, social media, Twitter, stigma, stigmatization, paranoiac

\section{INTRODUCTION}

Since Twitter entered our lives in 2006, it has provided its ever-increasing user base with participation, openness and speech opportunities without any space or time limitations. Twitter users can easily share their thoughts, experiences and images about any subject, including schizophrenia, an important public health problem. These posts, as well as the medical uses of the term "schizophrenia" and its related words, can offer a quick reflection of people's feelings and thoughts towards the disorder and its sufferers .

Stigmatization based on differentness diminishes the dignity of the victim, and elicits negative emotions and prejudiced behaviours in others towards them (1).
Stigmatization is frequently associated with disorders with complex aetiologies such as schizophrenia. To combat this stigmatization, it is not enough to have knowledge about stereotypes surrounding schizophrenia sufferers (i.e., that they are dangerous, weak in character, incurable, etc.) (2). Biased individuals endorse negative stereotypes (e.g. "That's right! Schizophrenia patients are prone to violence") and, as a result, display negative emotional reactions (e.g. "They scare me!") $(3,4)$. Contrary to stereotypes, prejudiced attitudes usually contain a negative assessment and cause emotional reactions (fear, anger, etc.) towards the stigmatized individuals. Prejudice leads 
to discriminatory behaviours (e.g., avoiding the prejudiced individual, preventing them from taking advantage of opportunities such as working, housing), and sometimes hostile behaviours against individuals with schizophrenia may be displayed due to negative emotions caused by prejudice (5).

Medically inappropriate explanations and statements about schizophrenia also increase the stigma. In addition, the words "schizophrenic" or "schizophrene", which are the adjective forms of schizophrenia, cause more negative emotions than the word "schizophrenia". These adjectives elicit a qualitative perception of the patients and consequently generate cognitive division in the form of "us" and "them", which is the essence of stigmatization. Humour and jokes made in social settings marginalize individuals diagnosed with schizophrenia, spread stereotypes and the reinforce hostile attitudes (6-8).

In studies conducted on societal perceptions, it was reported that half of the population felt that people with severe mental illness should be afraid of people with severe mental disorders; that these patients should be removed from society; that these patients were irresponsible; that it was appropriate for others to make decisions about the patients' lives; and that the patients were childish and needed serious care $(9,10)$. A study conducted by Arkar (1991) found that the participants had a tendency to interrupt or reduce interactions with individuals diagnosed with schizophrenia in environments requiring social intimacy, especially in cases such as sharing a house, being a next-door neighbour, working in the same workplace, or taking part in a social activity together.

It is possible to access publications and articles from the printed or visual media from the past that examine the attitudes, beliefs and perspectives of society towards schizophrenia and compare them with media sources of today, where information can be near instant via the internet. In the historical articles, negative attitudes, beliefs and stigmatization towards schizophrenia and patients diagnosed with schizophrenia are mentioned. In a study conducted in the USA in 2005, it was determined that $39 \%$ of the newspaper news about mental illnesses referred to dangerousness and violence (12). Crisp et al. (2000) stated that the violent news in the media caused the public to believe that individuals with schizophrenia are aggressive. The media's inaccurate and harmful information about mental disorders negatively affects the public's attitude towards patients and increases prejudice and stigmatization tendencies in society.

In this study, the perspective of society on schizophrenia and the issue of stigmatization was examined via Twitter, one of the most preferred social media outlets. Our data was sourced in a social environment where participants could express their thoughts in 280 character posts without outside influence, thus reflecting the belief and perspective of society in a natural way. In addition, since the majority of Twitter users are teenagers and young adults, who are a high-risk group for the onset of schizophrenia, it is very important to understand their knowledge, perceptions and attitudes regarding schizophrenia. As we noticed in Turkey, this forum's demographic increases the value of our study, which is the first work to be done in this area.

\section{MATERIAL AND METHOD}

This study was conducted over one month using a total of 1200 Twitter posts (tweets) containing the words "schizophrenia", "schizophrenic", "schizophrene", or "paranoiac". Tweets were selected by inputting these four keywords in the search tab of Twitter and noting the number of tweets containing each word (approximately 300 tweets per word). None of these tweets were retweets, and only those written in Turkish were taken into consideration.

The tweets were categorised into five separate groups:

1) Mocking/humorous use: Sentences ending with positive emojis (:), :)), :D); use of reference words such as "LOL", "haha", "hehe"; humorous, mocking or sarcastic tweets.

2) Negative use: Tweets with negative words such as "die", "hate", "torment", "mad", "maniac", "idiot", "dangerous", "terrible"; other tweets used to insult.

3) Inappropriate use: Misinformation about the disease; puzzling and ambiguous expressions; tweets attributing schizophrenia with symptoms of other diseases but not for negative or humorous purposes.

4) Anti-psychiatric opinion: Content indicating that psychiatric science is useless and unnecessary; that drugs make the condition worse and should not be used; or that a doctor should not be visited, etc.

5) Medically appropriate: Correct medical references to the disease; correct use of the signs or symptoms of this disease such as delusion, psychosis, cognitive impairment, hallucination, paranoia, correct information about treatment options; references or links to printed media reporting about individuals with the disease.

After grouping, the inter-rater reliability rates of these groups were examined by two researchers (ŞAK and YD). The inter-rater reliability analysis found high interpeer reliability in over 206 tweets (Cohen Kappa $=0.804$; $\mathrm{p}=0.001 ; \mathrm{CI}=95 \% 0.732-0.867)$. In addition, the profiles of the posters were examined one by one, and any shared information about age and gender was recorded. Then, statistical analyses were made using SPSS 18.0. 


\section{RESULTS}

We found that the contexts of these four words are most frequently "mocking/humorous" ( $\mathrm{n}=470,39.2 \%)$ or "negative" ( $n=312,26 \%)$. Inappropriate use was seen in $21.75 \%(n=261)$ of the tweets, and medically appropriate information in $11.4 \%(n=137)$. We found that the least number of tweets $(1.7 \%)$ were in an anti-psychiatric manner context $(\mathrm{n}=20)$ (Figure 1).

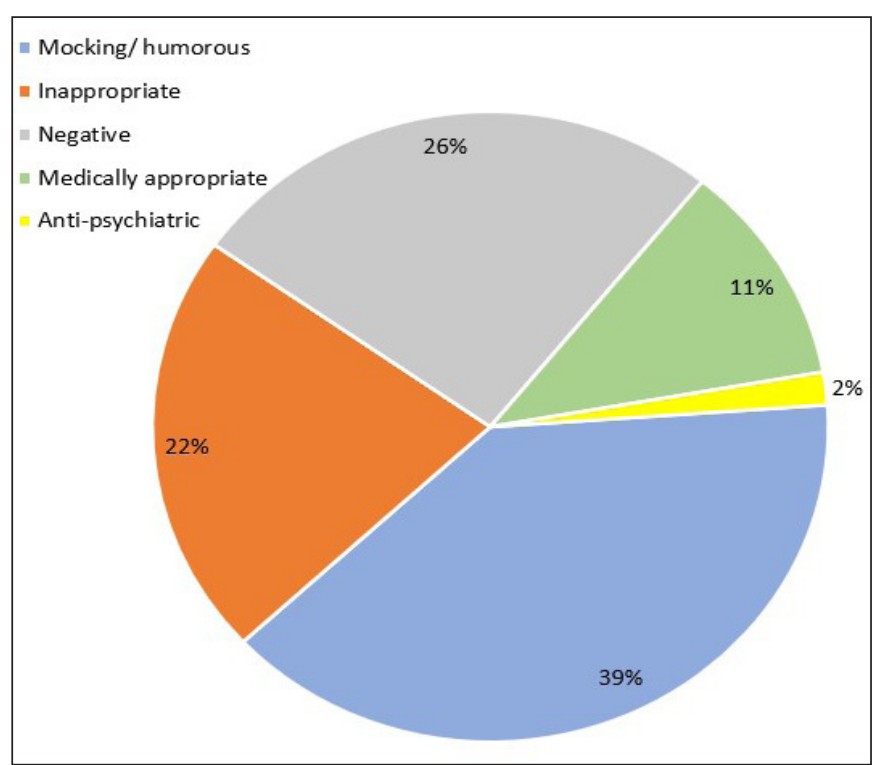

Figure 1. The proportion of 4 words according to the stigma type

When each word was examined separately, the most common negatively used word was "schizophrenic" (33.2\%). "Schizophrene" 29.4\% was the second most frequent (Figure 2). It was observed that "schizophrenic" (45.8\%) and "paranoiac" (39.3\%) were used most frequently in mocking/humorous contexts. We found that "schizophrenia" (26.7\%) was used most within a medically appropriate context .

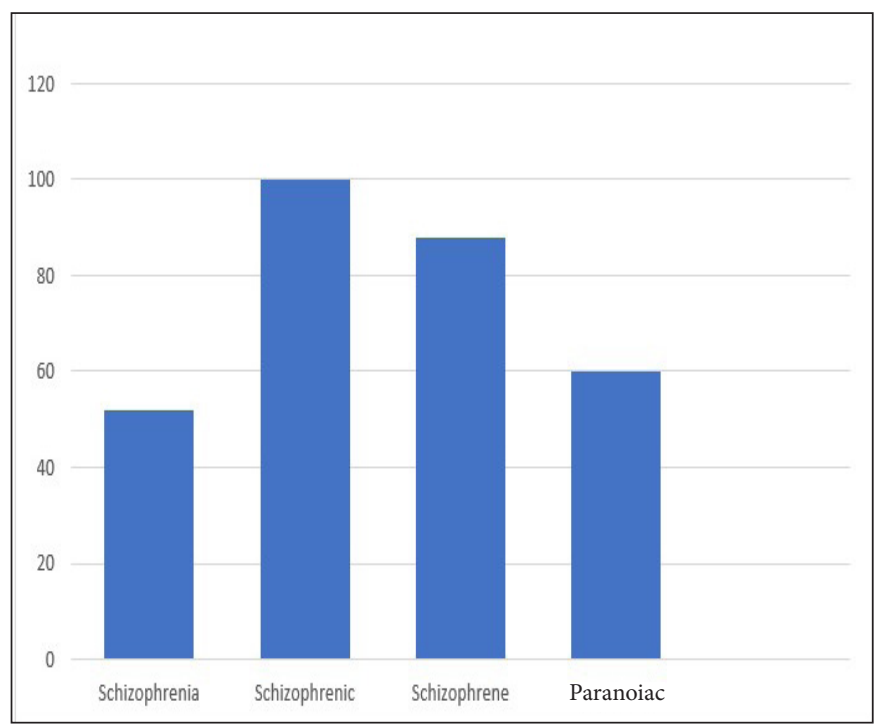

Figure 2. The proportion of 4 words according to "negative" type (n)
When evaluated in terms of gender, males mostly used these four words within mocking/humorous and negative contexts (39.5\% and $33.8 \%$, respectively), while females mostly used them in the contexts of mocking/humorous posts $(38.8 \%)$ or inappropriate use (25.6). It was found that medically appropriate use of these terms was twice as high by women as it was by men $(14.8 \%$ and $7.5 \%$, respectively) (Figure 3).

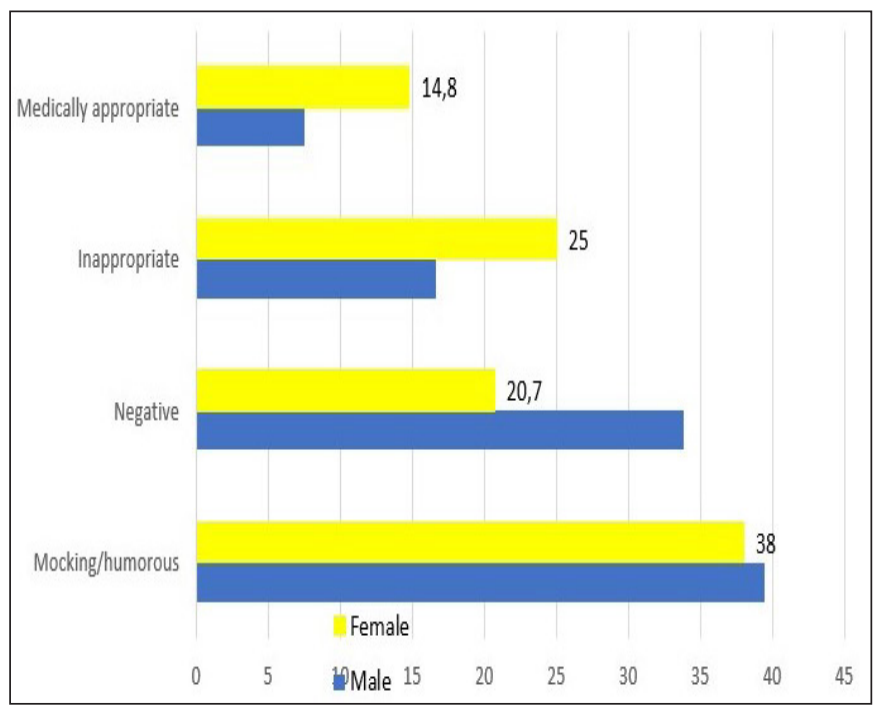

Figure 3. The proportion of 4 words usage according to gender (\%)

\section{DISCUSSION}

Our findings show that all four words-schizophrenia, schizophrene, schizophrenic, and paranoiac-are misused. It is also seen that misuse is more common in the word "schizophrenic", which is the adjective form of the word "schizophrenia". Although the medically appropriate use of "schizophrenia" is higher than other words, this word is also frequently used in a nonmedical way. Our findings coincide with previous studies conducted abroad in printed and social media $(14,15)$. In a similar study comparing schizophrenia and diabetes references on Twitter in 2015, it was noted that "schizophrenia" is generally used for negative, medically inappropriate, sarcastic and stigmatizing purposes compared to "diabetes", while "schizophrenic" is used more negatively and inappropriately than "schizophrenia" (15). In addition, Reavley et al. (2014) published a study on Twitter comparing schizophrenia and depression. They found that there was significantly more stigma against schizophrenia, and that $5 \%(n=451)$ of the detected schizophrenia tweets were stigmatizing. Our findings show that the main uses of the term "schizophrenia" on social media were inappropriate, negative, stigmatizing, and non-medical.

In our study, it was observed that mocking/humorous use of these terms was quite common. This form of use, 
especially in daily language, becomes an important part of the stigmatization process of individuals diagnosed with schizophrenia. With mocking or humorous use, the burden of the disease on the patient and their family is undervalued, and the individuals with schizophrenia are marginalized. The higher non-medical use of "schizophrenic" and "schizophrene" than "schizophrenia" may indicate that society does not know the name of the disorder correctly and that these uses are actually a part of stigmatization. Similarly, it can be said that the adjective forms of "schizophrenia" are used more negatively than "schizophrenia" itself. This kind of usage creates the cognitive fission of "us" and "them". It should also be kept in mind that the more frequent non-medical use of these four words may devalue the destructive symptoms of chronic mental diseases, which may add to stigmatization. As a result of the disconnection of "schizophrenia" and its related words from their medical contexts, the basic symptoms of schizophrenia become incomprehensible and may delay or prevent individuals and their families from seeking treatment $(15,17)$.

It was observed that men use these four words in a negative manner more often than women. Considering that women use the terms in a medically appropriate context at a higher rate than men, this may reflect the gender difference in social media users' perspectives on schizophrenia.

In a natural environment without influence on the individuals, the attitudes seen in the posts may be accurate reflections of the poster's thoughts and attitudes. The results of such studies are less affected by social attractiveness bias than the studies conducted on questionnaires, and can thus be very useful in terms of evaluating stigmatizing attitudes and attitudes (18). That the most common uses of the four key words of this study were non-medical may also indicate a deviated terminology usage.

One of the limitations of the study is that the sociodemographic characteristics of those who do not share the tweets are unknown. Twitter is mostly used by young people and young adults who live in cities and have a computer culture; thus, the sample may not reflect the whole society. However, we maintain that research on Twitter is a valuable means of understanding the attitudes and beliefs of adolescents and young adults .

Our analysis found that schizophrenia and related words were used in a stigmatizing way on Twitter. It is argued in the literature that other words should be used instead of schizophrenia to reduce stigmatization. However, Passerello et al. (2019) investigated the use of the words "psychosis" and "schizophrenia" in over 1120 tweets and found that the word "psychosis" is more stigmatized than "schizophrenia". This result refutes the claim that using the word "psychosis" instead of "schizophrenia" will reduce the risk of stigmatization.

\section{CONCLUSION}

This study shows that our society is lacking in knowledge about schizophrenia and that awareness of the effects of the disease is insufficient. In a period when accessing information and using social media has become so much easier, the lack of knowledge and attitude problems regarding mental disorders are an important issue. With the increasing importance of social media, the results of this study can help the efforts towards raising awareness, reducing stigma and providing information on helpful and accurate resources. In the fight against stigma, we believe that educating society, raising awareness and providing accurate information about the disease by collaborating with the media is an important responsibility of psychiatric associations and their colleagues. Attempts to end stigmatization on social media can play key roles in increasing the awareness of young people (future leaders), and can thus reduce stigmatization in future generations.

\section{ETHICAL DECLORATIONS}

Informed Consent: All patients signed the free and informed consent form.

Referee Evaluation Process: Externally peer-reviewed.

Conflict of Interest Statement: The authors have no conflicts of interest to declare.

Financial Disclosure: The authors declared that this study has received no financial support.

Author Contributions: All of the authors declare that they have all participated in the design, execution, and analysis of the paper, and that they have approved the final version.

Acknowledgements: Thanks to Büşra Yürümez Korkmaz, MD for her assistance in proofreading this manuscript.

\section{REFERENCES}

1. Sontag S. Ilness as Metaphor and AIDS and its Metaphors. UK, Blackstone Publishing; 2008.

2. Hamilton DL, Sherman JW. Stereotypes. In: Wyer RS Jr, Srull TK, editors. Handbook of social cognition, $2^{\text {nd }}$ ed. Hillsdale, Lawrence Erlbaum; 1994.

3. Devine PG. Stereotypes and prejudice: their automatic and controlled components. J Pers Soc Psychol 1989; 56: 5-18.

4. Eagly AH, Chaiken S. The social psychology of attitudes. Fort Worth, Harcourt Brace Jovanovich; 1993, p: 794. 
5. Crocker J, Major B, Steele C. Social stigma. In: Gilbert D, editor; Fiske ST, editor; Lindzey G, editor. The handbook of social psychology, 4th ed. Vol. 2. New York, McGraw- Hill; 1998.

6. Ford TE, Ferguson MA. Social consequences of disparagement humor: a prejudiced norm theory. Personal Soc Psychol Rev 2004; 8: 79-94.

7. Rüsch N, Angermeyer MC, Corrigan PW. Mental illness stigma: concepts, consequences, and initiatives to reduce stigma. Eur Psychiatry 2005; 20: 529-39.

8. Jorm AF, Oh E. Desire for social distance from people with mental disorders. Aust NZ J Psychiatry 2009; 43:183-200.

9. Taylor SM, Dear MJ. Scaling community attitudes toward the mentally ill. Schizophr Bull 1980; 7: 225-40.

10. Brockington I. Hall P. Levings J, Murphy C. The community's tolerance of the mentally ill. Br J Psychiatry 1993; 162: 93-9.

11. Arkar H. Akıl hastasının sosyal reddedilimi. Düşünen Adam Derg 1991; 4: 6-9.

12.Corrigan PW, Watson AC, Gracia G, Slopen N, Rasinski K, Hall LL. Newspaper stories as measures of structural stigma. Psychiatr Serv 2005; 56: 551-6.

13. Crisp AH, Gelder MG, Rix S, Meltzer HI. Stigmatisation of people with mental illnesses. Br J Psychiatry 2000; 177: 4-7.

14.Link, BG, Yang LH, Phelan JC, Collins PY. Measuring mental illness stigma. Schizophr Bull 2004; 30: 511-41.

15. Joseph AJ, Tandon N, Yang LH, et al. \#Schizophrenia: use and misuse on Twitter. Scizophr Res 2015; 165: 111-5.

16. Reavley NJ, Pilkington PD. Use of Twitter to monitor attitudes toward depression and schizophrenia: an exploratory study. Peer J 2014; 2: e647

17.Link BG, Phelan JC. Conceptualizing stigma. Annu Rev Sociol 2001; 27: 363-85.

18. Reavley NJ, Jorm AF. Stigmatizing attitudes towards people with mental disorders: findings from an Austrialian National Survey of Mental Health Literacy and Stigma. Aust N Z J Psychiatry 2001; 48: 1086-93.

19. Passerello GL, Hazelwood JE, Lawrie S. Using Twitter to assess attitudes to schizophrenia and psychosis. BJPsych Bull 2019; 43: 158-66. 